\title{
The importance of targets and value creation in vertical acquisitions
}

\author{
Manapol Ekkayokkaya* \\ Chulalongkorn Business School \\ Chulalongkorn University \\ Thailand \\ Manapol@cbs.chula.ac.th
}

\author{
Krishna Paudyal \\ Department of Accounting and Finance \\ University of Strathclyde \\ United Kingdom \\ Krishna.paudyal@strath.ac.uk
}

We thank Tom Connelly, Ruttachai Seelajaroen, Sira Suchintabandid, and especially, the editor and anonymous referee for valuable comments and suggestions. Manapol Ekkayokkaya appreciates a research grant from the Faculty of Commerce and Accountancy, Chulalongkorn University.

*Corresponding author: Department of Banking and Finance, Chulalongkorn Business School, Chulalongkorn University, Bangkok 10330, Thailand. 


\title{
The importance of targets and value creation in vertical acquisitions
}

\begin{abstract}
We study how value creation in vertical acquisitions varies in the importance of the target's assets to its acquirer. The synergistic gain increases in the degree of vertical relatedness between the acquirer and target industries. This finding suggests that the importance of the target firm's assets to its acquirer's productivity is an important valuecreating channel in vertical acquisitions. We also find evidence suggesting that acquirers extract greater value as the synergistic gain increases, consistent with an efficient investment incentive underlying the integration decision.
\end{abstract}

Keywords: $\quad$ Vertical acquisitions, vertical integration, vertical relatedness, synergy

JEL Classification: G34, L22, G14 


\section{The importance of targets and value creation in vertical acquisitions}

Vertical acquisitions have long been known to both practitioners and academics since 1920s (Weston et al., 2004). Grossman and Hart (1986) demonstrate that it is optimal for a party in writing an incomplete contract to take ownership of, i.e., integrate, relationship-specific assets if the assets are more important to its productivity than to the other party's. Accordingly, a key mechanism underlying value creation in vertical acquisitions is the importance of the target's assets to the acquirer's productivity. Despite its theoretical foundation and the renown of vertical acquisitions, the empirical validity of this fundamental implication thus far appears unknown. As Bresnahan and Levin (2013) note, a specific prediction of the theory has been subjected to only little empirical investigation.

We explore how value creation in vertical acquisitions varies in the importance of a target firm to its acquirer. In the Grossman and Hart (1986) model, the rationale behind integration when assets are important to the firm is that integration yields a higher marginal return on investment than non-integration would: the more important the assets are to the firm, the greater is the benefit of integration. For a given vertical acquisition that is made, the Grossman and Hart model therefore implies that the value of the acquisition increases in the importance of the target firm's assets to the acquirer.

Notably, Grossman and Hart (1986) assume efficient investment incentives and do not distinguish between control and ownership. Firms, especially publicly traded firms, are often characterized by the control-ownership separation and agency problems (e.g., Fama, 1980). To further understand the efficiency of acquirers' decision to integrate a target that is important to their productivity, we also explore how much 
value acquirers extract from vertical acquisitions. An efficient integration incentive predicts that the value extracted by acquirers increases in the integration benefit.

To date, evidence on the value impact of vertical acquisitions seems sparse (Fan and Goyal, 2006; Kedia et al., 2011), and much of the empirical literature focuses on the determinants of integration decisions (e.g., Acemoglu et al., 2009; Ahern and Harford, 2014). We extend the literature by investigating the role the importance of a target firm to its acquirer plays in vertical acquisitions, which is a fundamental but as yet unexplored mechanism for value creation. As noted by Bresnahan and Levin (2013), such paucity is likely due to the difficulty in measuring the importance of a given asset to a firm's activities. We address this difficulty by employing an intuitive and exogenous proxy for the importance of a target's activities to its acquirer's activities.

\section{Data and methodology}

We draw our sample of completed vertical acquisitions announced between January 1990 and December 2010 from the SDC U.S. M\&A database. We identify vertical acquisitions as transactions involving an acquirer and target with different primary 2digit SIC codes where the Fan and Lang (2000) measure of vertical relatedness between the firms' IO industries is greater than zero. ${ }^{1,2}$ The transaction value must be at least $\$ 1$

\footnotetext{
${ }^{1}$ For many firms, their SIC codes change over time. To allow for changes in the SIC code, we use the codes reported at the time of bid announcement by the SDC. The SIC codes provided by Compustat are the latest codes and ones accessible to researchers, which may differ from the firm's industrial structure in prior years.

2 We also rerun our tests requiring, as in prior studies (e.g., Fan and Goyal, 2006), the measure to be above $1 \%$, and find similar results (untabulated). All of the untabulated results are available on request. This measure of vertical relatedness uses the industry input-output (IO) data provided by the Bureau of Economic Analysis (BEA). The BEA updates its survey and IO data every five years. Thus, we match the IO definitions in the 1987 survey to the sample transactions during 1990-1991. Similarly, the 1992 definitions are matched to transactions made during 1992-1996, the 1997 definitions to transactions made during 1997-2001, and so on. The BEA uses the SIC codes for the surveys conducted prior to 1997, and the NAICS codes for the 1997 survey onwards. Similar to Ozbas and Scharfstein (2010), we therefore use the SIC codes for matching the IO definitions to the transactions made before 1997, and use the NAICS codes for the transactions made in 1997 onwards.
} 
million. The acquirer must be a publicly listed firm recorded on the CRSP and Compustat files, and hold less than $50 \%$ of ownership in the target before acquisition. In total, 6,465 transactions by 2,968 unique acquirers survive these sample criteria. In $96 \%$ of the full sample, the acquirer owns more than $50 \%$ of the target after acquisition suggesting that vertical acquisitions represent transfers of residual control rights. ${ }^{3}$ In $1,884(2,511)$ transactions, the acquirer makes at least one prior transaction during the preceding year (two years), i.e., is a frequent acquirer.

Our proxy for the importance of a target firm's activities to its acquirer's activities is the Fan and Lang (2000) measure, which is a widely adopted measure of vertical relatedness. The degree of vertical relatedness between the industries of an acquirer and its target $(V)$ should reflect the extent to which an acquirer relies on its target as either a supplier or customer: the larger the relatedness the larger is the reliance. ${ }^{4}$ Also importantly, this measure should be exogenous to firm-specific characteristics that potentially drive firms' decision to make an acquisition, and hence, to the expected value creation (i.e., synergy). Production relatedness between industries depends on the production functions for the goods produced by the industries, not by the expected outcome of decisions by individual firms.

We measure value creation in acquisitions as the synergistic gain, i.e., the combined announcement-period gain to the acquirer and target. Because a large portion of our sample acquirers are frequent acquirers, we estimate an announcement-period gain as the market-adjusted excess return during the 5-day window $(-2,+2)$

\footnotetext{
${ }^{3}$ Our main analysis is based on the full sample. When using only full acquisitions, results (untabulated) remain similar.

${ }^{4}$ Using product descriptions in firms' 10-K filings, Hoberg and Phillips $(2010,2016)$ propose a text-based measure of relatedness between a pair of firms. This measure is designed to capture horizontal relatedness between peers, rather than customer-supplier vertical relatedness. It is therefore not applicable to the objective of our study, which is to analyze vertical acquisitions.
} 
surrounding the announcement date (for a detailed discussion on this approach, see, e.g., Fuller et al., 2002). To empirically investigate how much value acquirers extract from in vertical acquisitions, we also analyze the announcement-period gains to acquirers.

\section{INSERT TABLE 1 ABOUT HERE}

Panel A of Table 1 shows that the average combined, i.e., synergistic, gain $(1.44 \%)$ is significantly positive. ${ }^{5}$ Hence, vertical acquisitions typically create significant value: i.e., the integration benefit is on average positive. Consistent with the liquidity effect (e.g., Officer et al., 2007), acquirers make a small loss $(-0.57 \%)$ when buying a listed target but a material gain (2.18\%) when buying an unlisted target. As shown in Panel B, $V$ is clustered at low levels. Fifty-four percent of the full sample $(3,498$ transactions) have $V$ of $1 \%$ or less. The fraction is $61 \%$ for listed-target acquisitions: Fan and Goyal (2006) report a 65\% figure for the 1962-1996 period. Considering that production of a given good requires numerous inputs, the clustering of $V$ at low levels is not surprising. Moreover, Fan and Goyal note that because the IO data is based on the value of shipments (which includes value-added items and profit margin), even $V$ of $1 \%$ is economically large. Panel B also suggests that the combined gain tends to increase in $V$. While the gain pattern appears in a similar direction for acquirers of listed targets, it is indiscernible for unlisted-target acquirers.

To examine the relation between $V$ and the integration benefit, we employ regression models of the following general form:

\footnotetext{
${ }^{5}$ The median gains (untabulated) are similar. Because the combined gain can be estimated only for the transactions involving a listed target, the sample size for this analysis is 866 acquisitions.
} 
where $A G_{i}$ is the combined announcement-period gain on acquisition $i$. Given the distribution of $V_{i}$ observed in Table 1 , we use $\ln \left(1+V_{i}\right)$ as a regressor. ${ }^{6} X_{i, j}$ is a $(k-1)$ dimensional vector of control variables standard in the M\&A literature (e.g., Moeller et al., 2004), which include industry (acquirer 2-digit SIC code) and year dummy variables. We also seek to account for the potential influence of asset tangibility and R\&D intensity, which have been reported as important determinants of vertical integration decisions (Williams, 2012; Frésard, et al., 2017).7 See notes to Table 2 for the variable definitions.

\section{Empirical results}

Table 2 reports the regression results based on equation (1) with the combined gain as the dependent variable. The hypothesis that the value of vertical acquisitions increases in the importance of the target to its acquirer predicts a positive sign for $\hat{\beta}_{1}$. Model (1) is the baseline model, i.e., without control variables. Model (2) incorporates the control variables. In both models, $\hat{\beta}_{1}$ is significantly positive. To account for the effects of unobservable time-invariant firm-specific factors that may drive firms to pursue vertical acquisitions, in model (3) we replace industry fixed effects with firm fixed effects (see, e.g., Golubov et al., 2015). Notably, the adjusted $R^{2}$ is substantially

\footnotetext{
${ }^{6}$ Results (untabulated) remain similar when using non-transformed $V_{i}$ as a regressor. Consistent with the relatively large impact of the natural log transformation on small decimal values, results remain in the same direction with weaker significance when using $\ln \left(V_{i}\right)$.

${ }^{7}$ Since acquirers in $53.6 \%$ (3,464 deals) of our sample deals do not make R\&D expenditure, we use a dummy variable as a proxy for R\&D intensity in our main analysis. Nevertheless, we rerun all of our regression analyses using the ratio of $R \& D$ expenditure to total assets and find similar results.
} 
larger in model (3) than in models (1) and (2), indicating important influences of

unobservable firm-specific factors. Yet, $\hat{\beta}_{1}$ remains significantly positive in model (3). ${ }^{8}$

\section{INSERT TABLE 2 ABOUT HERE}

For the control variables, the results for the known determinants of synergistic gains in model (2) are broadly in line with the existing literature. However, the results in model (3) often differ from prior studies. The deviation may be attributable to the inclusion of firm fixed effects. ${ }^{9}$ The coefficients on asset tangibility and R\&D indicator suggest that these two known determinants of vertical integration decisions are unlikely to have important influence on synergistic gains. Despite the presence of control variables including firm fixed effects, the significantly positive sign of $\hat{\beta}_{1}$ remains intact. The Table 2 results indicate that the synergistic gain from vertical acquisitions, i.e., the integration benefit, increases in $V$ (our proxy for the importance of a target firm to its acquirer)..$^{10}$

Next, we investigate whether acquirers in vertical acquisitions extract a larger gain as the integration benefit increases. To do so, we estimate equation (1) with acquirers' gain as the dependent variable. Given that the integration benefit increases in

\footnotetext{
8 We use the primary segments in identifying vertical acquisitions. Doing so excludes from our analysis the potential effects of combinations of the secondary divisions, whether the combination is vertical or horizontal. Fan and Goyal (2006) report that the wealth effects of vertical acquisitions based on the primary segments are unaffected by combination at the secondary level. Moreover, our relatedness measure $(V)$ is built on the primary segments. Thus, the effect of horizontal combination at the secondary level, if dominant in our sample, is to tilt our analysis towards finding an insignificant $\hat{\beta}_{1}$. Accordingly, our evidence can be viewed as a conservative estimate for the impact of vertical relatedness on gains from vertical acquisitions. To the extent that our sample is representative of the population of vertical acquisitions, our findings also should be generalizable to vertical integrations at the secondary level. ${ }^{9}$ The results for the known gain determinants in Table 3 also often deviate from prior studies. For the Table 3 analysis, when we replace firm fixed effects with industry fixed effects, results (untabulated) become more in line with the extant evidence. To save space, we discuss only the key results in Table 3. ${ }^{10}$ Since the combined gain is a sum of the acquirer gain and target gain, this finding is unaffected by the relative bargaining positions of an acquirer and its target.
} 
$V$, such value extraction by acquirers predicts a positive sign for $\hat{\beta}_{1}$, i.e., a positive relation between $\ln \left(1+V_{i}\right)$ and acquirers' gain. For this investigation, we focus on the specification of model (3) in Table 2 because it is most robust as an empirical specification. Results are reported in Table 3.

\section{INSERT TABLE 3 ABOUT HERE}

In model (1), the dependent variable is the gain to acquirers of listed targets, and $\hat{\beta}_{1}$ is significantly positive. Although a typical listed-target acquirer suffers a small loss (see Panel A of Table 1), the positive sign of $\hat{\beta}_{1}$ indicates that the loss becomes smaller as the production activities of an acquirer and its target become more vertically related. Given that the integration benefit (i) is on average positive as observed in Panel A of Table 1 and (ii) increases in the importance of a target firm to its acquirer as observed in Table 2, the model (1) result is consistent with the value extracted by acquirers increasing in the size of the integration benefit.11

Because the vast majority of the M\&A population, as well as our sample, involves an unlisted target, we also analyze unlisted-target acquisitions. As shown in model (2), $\hat{\beta}_{1}$ becomes insignificant when targets are unlisted firms. For this seemingly puzzling result, one plausible explanation lies in the human capital element in relationshipspecific investments. To the extent that vertical acquisitions of privately held firms

\footnotetext{
11 Unlike the combined gain, acquirer gains are affected by the relative bargaining power of an acquirer and its target. The losses to listed-target acquirers observed in Table 1 suggest that these acquirers, whether they be a supplier or a customer, typically have less bargain power against their target. To this extent, the model (1) result implies that the value extracted by listed-target acquirers increases in the integration benefit, even though they typically have relatively weak bargaining power. The gains to unlisted-target acquirers (see Table 1) indicate that this group of acquirers typically have strong bargaining power against their target. Given the model (2) result reported below, there is no evidence that unlisted-target acquirers, despite their relatively strong bargaining power, extract a larger gain as the integration benefit becomes larger.
} 
reflect a response to incomplete contracting for human skills, know-how, or soft information (see Kohers and Ang, 2001), the measure of vertical relatedness we adopt is likely to contain a nontrivial measurement error: the measure is built on the IO data, which accounts only for the input and output of commodity flows.

In sum, the Table 2 results provide evidence that the value creation in vertical acquisitions, i.e., benefit of integration, increases in the importance of a target firm's assets to its acquirer's productivity. The result from model (1) of Table 3 suggests that the acquiring party extracts greater value as the integration benefit increases. Such value extraction lends support to efficient investment incentives of the acquiring party assumed in Grossman and Hart (1986), and also provides a rationale for the significant synergistic gain observed in Table 1.

\section{Result stability across time}

Our sample period extends over two decades. Despite the known merits of a long sample period, result stability across sub-periods is a natural issue. Kedia et al. (2011) report that the combined gain from vertical acquisitions is positive during 1979-1997 but becomes insignificant during 1998-2002. We re-estimate the announcement-period gains and key regression models for various sub-periods. Untabulated results show that the combined gain (1.42\%) is significant during 1990-2002, which is the overlap between Kedia et al.'s sample period and ours. The combined gain also remains significant and similar in size during 1990-1997, 1998-2002 as well as 2003-2010.12 Across these sub-periods, the losses to listed-target acquirers are comparable (ranging

\footnotetext{
${ }^{12}$ For the period 1998-2002, Kedia et al.'s (2011) result and ours vary. This is plausibly due to the difference in sample screening. While Kedia et al. impose a minimum level of relatedness (i.e., $1 \%$ ) in defining vertical acquisitions, we analyze all acquisitions with $V$ greater than zero.
} 
from $-0.67 \%$ to $-0.45 \%$ ), and the gains to unlisted-target acquirers remain persistently significant (ranging from $1.56 \%$ to $2.82 \%$ ).

Importantly, $\hat{\beta}_{1}$ from re-estimating model (3) of Table 2 is significantly positive not only during 1990-2002, but also during 1990-1997 and 1998-2002. Although $\hat{\beta}_{1}$ becomes insignificant during 2003-2010, it remains positive and similar in size. Across these sub-periods, a similar pattern is observed when rerunning model (1) of Table 3. $\hat{\beta}_{1}$ from rerunning model (2) of Table 3 remains insignificant in all of the sub-periods. Overall, our key results are similar across sub-periods.

\section{Conclusions}

We document evidence on a fundamental mechanism through which vertical acquisitions create value, which has thus far remained largely unexplored. The synergistic gain is positively related to the degree of vertical relatedness between the acquirer and its target. Consistent with the Grossman and Hart (1986) model, this finding suggests that the benefit of vertical integration through an ownership transfer increases in the importance of incontractible relationship-specific investments to the acquiring firm. Although our sample acquirers are publicly traded firms, and hence, characterized by the control-ownership separation, our analysis also indicates that acquirers' incentive to vertically integrate their target is typically efficient. 


\section{References}

Acemoglu, D., Johnson, S., Mitton, T., 2009. Determinants of vertical integration: financial development and contracting costs. Journal of Finance 63, 1251-1290.

Ahern, K.R., Harford, J., 2014. The importance of industry links in merger waves. Journal of Finance 69, 527-576.

Bresnahan, T.F., Levin, J.D., 2013. Vertical integration and market structure, in Gibbons, R., Roberts, J., eds.: Handbook of Organizational Economics (Princeton University Press, Princeton, NJ).

Fama, E.F., 1980. Agency problems and the theory of the firm. Journal of Political Economy 88, 288-307.

Fan, J.P.H., Goyal, V.K., 2006. On the patterns and wealth effects of vertical mergers. Journal of Business 79, 877-902.

Fan, J., Lang, L., 2000. The measurement of relatedness: An application to corporate diversification. Journal of Business 73, 629-660.

Frésard, L., Hoberg, G., Phillips, G., 2017. Innovation activities and integration through vertical acquisitions. Working paper.

Fuller, K., Netter, J., Stegemoller, M., 2002. What do returns to acquiring firms tell us? Evidence from firms that make many acquisitions. Journal of Finance 57, 1763-1793.

Golubov, A., Yawson, A., Zhang, H., 2015. Extraordinary acquirers. Journal of Financial Economics 116, 314-330.

Grossman, S.J., Hart, O.D., 1986. The costs and benefits of ownership: A theory of vertical and lateral integration. Journal of Political Economy 94, 691-719.

Hoberg, G., Phillips, G., 2010. Product market synergies and competition in mergers and acquisitions: A text-based analysis. Review of Financial Studies 23, 3773-3811.

Hoberg, G., Phillips, G., 2016. Text-based network industry classifications and endogenous product differentiation. Journal of Political Economy 124, 1423-1465.

Kedia, S., Ravid, S.A., Pons, V., 2011. When do vertical mergers create value? Financial Management 40, 845-877.

Kohers, N., Ang, J., 2001. Earnouts in mergers: Agreeing to disagree and agreeing to stay. Journal of Business 73, 445-476.

Moeller, S.B., Schlingemann, F.P., Stulz, R.M., 2004. Firm size and gains from acquisitions. Journal of Financial Economics 73, 201-228. 
Officer, M.S., 2007. The price of corporate liquidity: Acquisition discounts for unlisted targets. Journal of Financial Economics 83, 571-598.

Ozbas, O., Scharfstein, D.S., 2010. Evidence on the dark side of internal capital markets. Review of Financial Studies 23, 581-599.

Weston, J.F., Mitchell, M.L., Mulherin, J.H., 2004. Takeovers, Restructuring, and Corporate Governance $4^{\text {th }}$ ed. Upper Saddle River, NJ: Pearson Prentice Hall.

Williams, R., 2012. Vertical firm boundaries: Supplier-customer contracts and vertical integration. Working paper. 


\section{Table 1 \\ Descriptive statistics}

The number of acquisitions, and average announcement-period gains to combined firms and to acquirers of listed targets and acquirers of unlisted targets are reported. Panel A reports statistics for the full sample. Panel B reports statistics for subsamples by the degree of vertical relatedness $(\mathrm{V})$. In brackets is sample size. ${ }^{* *}, * *$, and ${ }^{*}$ denote statistical significance at the $1 \%, 5 \%$, and $10 \%$, respectively.

\begin{tabular}{|c|c|c|c|c|}
\hline & \multirow[b]{3}{*}{$\begin{array}{r}\text { Number of } \\
\text { acquisitions }\end{array}$} & \multicolumn{3}{|c|}{ Announcement-period gains (\%) } \\
\hline & & \multirow[b]{2}{*}{ Combined } & \multicolumn{2}{|c|}{ Acquirers of } \\
\hline & & & $\begin{array}{l}\text { Listed } \\
\text { targets }\end{array}$ & $\begin{array}{r}\text { Unlisted } \\
\text { targets }\end{array}$ \\
\hline \multicolumn{5}{|l|}{ Panel A: Full sample } \\
\hline All & 6465 & $\begin{array}{l}1.44^{* * *} \\
{[866]}\end{array}$ & $\begin{array}{l}-0.57^{* *} \\
{[866]}\end{array}$ & $\begin{array}{l}2.18^{* * *} \\
{[5599]}\end{array}$ \\
\hline \multicolumn{5}{|c|}{ Panel B: Subsamples by degree of relatedness (\%) } \\
\hline $0.0<V \leq 0.5$ & 2404 & $\begin{array}{l}0.99 * * \\
{[370]}\end{array}$ & $\begin{array}{l}-0.69 * \\
{[370]}\end{array}$ & $\begin{array}{l}2.08^{* * *} \\
{[2034]}\end{array}$ \\
\hline $0.5<V \leq 1.0$ & 1094 & $\begin{array}{l}1.20^{* *} \\
{[160]}\end{array}$ & $\begin{array}{l}-0.65 \\
{[160]}\end{array}$ & $\begin{array}{l}2.52^{* * *} \\
{[934]}\end{array}$ \\
\hline $1.0<V \leq 2.5$ & 1483 & $\begin{array}{l}1.88^{* * * *} \\
{[165]}\end{array}$ & $\begin{array}{l}-0.61 \\
{[165]}\end{array}$ & $\begin{array}{l}2.21^{* * *} \\
{[1318]}\end{array}$ \\
\hline $2.5<V \leq 5.0$ & 788 & $\begin{array}{l}2.66^{* * *} \\
{[86]}\end{array}$ & $\begin{array}{l}0.45 \\
{[86]}\end{array}$ & $\begin{array}{l}2.05^{* * *} \\
{[702]}\end{array}$ \\
\hline $5.0<V \leq 10.0$ & 369 & $\begin{array}{l}4.05^{*} \\
{[31]}\end{array}$ & $\begin{array}{l}1.12 \\
{[31]}\end{array}$ & $\begin{array}{l}1.91^{* * *} \\
{[338]}\end{array}$ \\
\hline $10.0<V \leq 20.0$ & 216 & $\begin{array}{r}-0.72 \\
{[38]}\end{array}$ & $\begin{array}{r}-2.43 \\
{[38]}\end{array}$ & $\begin{array}{l}1.83^{* * *} \\
{[178]}\end{array}$ \\
\hline $20.0<V$ & 111 & $\begin{array}{l}3.09 * \\
{[16]}\end{array}$ & $\begin{array}{r}-0.69 \\
{[16]}\end{array}$ & $\begin{array}{l}3.15^{* * *} \\
{[95]}\end{array}$ \\
\hline
\end{tabular}




\section{Table 2 \\ Vertical relatedness and the combined announcement-period gain}

The dependent variable in all models is the combined announcement-period gain. $V$ is the degree of vertical relatedness. For acquirer characteristics: firm size is $\ln$ (book total assets); Tobin's $q$ is firm market value divided by book total assets; leverage is book total debt scaled by firm market value; free cash flow is EBITDA minus capital expenditure scaled by firm market value. Relative size is the transaction value scaled by acquirer equity market cap. Target industry liquidity is the value of all acquisitions made within the target's 2-digit SIC industry and year divided by total book assets of all Compustat firms in the same industry and year (Moeller et al., 2004). Asset tangibility is the ratio of tangible assets to total book assets. The cash and stock dummy variables are 1(0) if the transaction is financed purely, respectively, with cash and with stock (otherwise). R\&D is $1(0)$ if the acquirer makes (does not make) R\&D expenditure. In parentheses is $p$-value based on the White standard errors robust to clustering at the acquirer level.

\begin{tabular}{|c|c|c|c|}
\hline Explanatory variables & (1) & (2) & (3) \\
\hline \multirow[t]{2}{*}{$\ln \left(1+V_{i}\right)$} & 7.064 & 7.497 & 9.064 \\
\hline & $(0.047)$ & $(0.086)$ & $(0.033)$ \\
\hline \multirow[t]{2}{*}{ Firm size } & & -0.579 & 1.082 \\
\hline & & $(0.007)$ & $(0.233)$ \\
\hline \multirow[t]{2}{*}{ Tobin's $q$} & & 0.340 & 3.359 \\
\hline & & $(0.587)$ & $(0.070)$ \\
\hline \multirow[t]{2}{*}{ Leverage } & & 3.446 & 14.264 \\
\hline & & $(0.110)$ & $(0.024)$ \\
\hline \multirow[t]{2}{*}{ Free cash flow } & & 12.277 & 17.554 \\
\hline & & $(0.120)$ & $(0.191)$ \\
\hline \multirow[t]{2}{*}{ Cash } & & 1.791 & 0.370 \\
\hline & & $(0.005)$ & $(0.653)$ \\
\hline \multirow[t]{2}{*}{ Stock } & & -0.154 & 0.643 \\
\hline & & $(0.850)$ & $(0.564)$ \\
\hline \multirow[t]{2}{*}{ Relative size } & & 0.164 & 0.077 \\
\hline & & $(0.449)$ & $(0.809)$ \\
\hline \multirow[t]{2}{*}{ Target industry liquidity } & & 0.118 & -0.049 \\
\hline & & $(0.642)$ & $(0.894)$ \\
\hline \multirow[t]{2}{*}{ Asset tangibility } & & -0.686 & -3.585 \\
\hline & & $(0.707)$ & $(0.529)$ \\
\hline \multirow[t]{2}{*}{$R \& D$} & & -1.146 & 0.261 \\
\hline & & $(0.241)$ & $(0.896)$ \\
\hline \multirow[t]{2}{*}{ Constant } & 1.278 & 4.516 & -11.564 \\
\hline & $(0.000)$ & $(0.133)$ & $(0.181)$ \\
\hline Industry fixed effects & & yes & \\
\hline Year fixed effects & & yes & yes \\
\hline Firm fixed effects & & & yes \\
\hline Adjusted $R^{2}(\%)$ & 0.15 & 5.87 & 43.03 \\
\hline No. of observations & 866 & 866 & 866 \\
\hline
\end{tabular}




\section{Table 3}

\section{Vertical relatedness and the announcement-period gains to acquirers}

Acquirer announcement-period gain is regressed against vertical relatedness and control variables. The dependent variable in model (1) is the announcement-period gain to acquirers of listed targets, and in model (2) is the announcement-period gain to acquirers of unlisted targets. The explanatory variables are defined as in Table 2. In parentheses is $p$-value based on the White standard errors robust to clustering at the acquirer level.

\begin{tabular}{|c|c|c|}
\hline Explanatory variables & $\begin{array}{l}\text { Acquirers of } \\
\text { listed targets }\end{array}$ & $\begin{array}{l}\text { Acquirers of } \\
\text { unlisted targets }\end{array}$ \\
\hline \multirow[t]{2}{*}{$\ln \left(1+V_{i}\right)$} & 8.514 & -1.657 \\
\hline & $(0.032)$ & $(0.603)$ \\
\hline \multirow[t]{2}{*}{ Firm size } & 1.503 & -0.874 \\
\hline & $(0.141)$ & $(0.078)$ \\
\hline \multirow[t]{2}{*}{ Tobin's $q$} & 4.911 & -0.759 \\
\hline & $(0.048)$ & $(0.328)$ \\
\hline \multirow[t]{2}{*}{ Leverage } & 19.896 & 4.880 \\
\hline & $(0.029)$ & $(0.058)$ \\
\hline \multirow[t]{2}{*}{ Free cash flow } & 21.102 & -16.270 \\
\hline & $(0.237)$ & $(0.002)$ \\
\hline \multirow[t]{2}{*}{ Cash } & 1.051 & 0.460 \\
\hline & $(0.235)$ & $(0.186)$ \\
\hline \multirow[t]{2}{*}{ Stock } & 1.064 & 1.517 \\
\hline & $(0.391)$ & $(0.093)$ \\
\hline \multirow[t]{2}{*}{ Relative size } & -0.506 & 0.538 \\
\hline & $(0.121)$ & $(0.001)$ \\
\hline \multirow[t]{2}{*}{ Target industry liquidity } & -0.161 & -0.077 \\
\hline & $(0.704)$ & $(0.653)$ \\
\hline \multirow[t]{2}{*}{ Asset tangibility } & -8.368 & 2.223 \\
\hline & $(0.217)$ & $(0.443)$ \\
\hline \multirow[t]{2}{*}{$\mathrm{R} \& \mathrm{D}$} & 2.629 & 1.244 \\
\hline & $(0.251)$ & $(0.425)$ \\
\hline \multirow[t]{2}{*}{ Constant } & -18.517 & 2.125 \\
\hline & $(0.061)$ & $(0.645)$ \\
\hline Year fixed effects & yes & yes \\
\hline Firm fixed effects & yes & yes \\
\hline Adjusted $R^{2}(\%)$ & 39.14 & 29.03 \\
\hline No. of observations & 866 & 5599 \\
\hline
\end{tabular}

